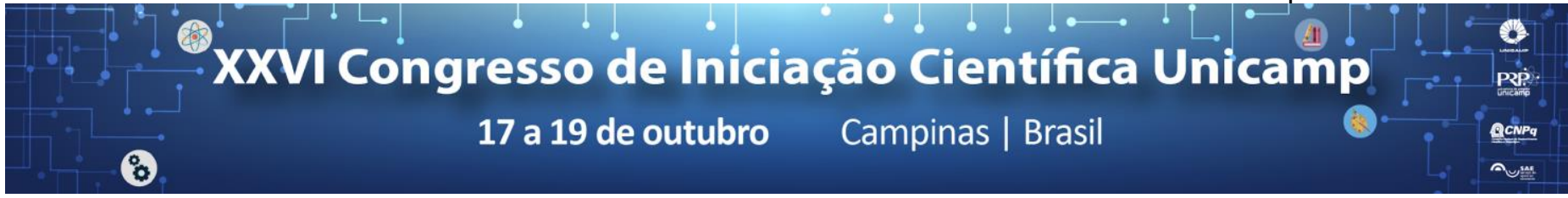

\title{
SENTIMENTOS PATERNOS ACERCA DA HOSPITALIZAÇÃO DO FILHO EM UNIDADE DE INTERNAÇÃO NEONATAL
}

\section{Vitória Fermino*, Profa Dra Elenice Valentim Carmona}

\section{Resumo}

No contexto da internação neonatal, o pai também deve ter suas necessidades compreendidas e assistidas. Objetivo: Descrever os sentimentos paternos acerca da hospitalização do filho em Unidade de Internação Neonatal. Descrição metodológica: Estudo exploratório-descritivo e qualitativo, com coleta de dados sendo realizada por meio de entrevistas semiestruturadas, analisadas segundo Análise Temática de Conteúdo proposta por Minayo. Parecer do CEP no 1.387.229. Resultados: Foram entrevistados 21 pais. Das entrevistas emergiram três categorias temáticas: 1) Sentimentos paternos; 2) Hospitalização como experiência árdua e 3) Enfrentamento da hospitalização por meio da fé. Conclusão: Os pais vivenciam sentimentos intensos e os profissionais de enfermagem podem ser facilitadores para que a paternidade no contexto da hospitalização possa ser vivenciada de forma mais positiva. Assim, o cuidado intencional e direcionado aos pais poderá atenuar sentimentos negativos e favorecer os positivos que emergiram nos discursos do presente estudo.

\section{Palavras-chave:}

Pai, Recém-nascido, Unidades de Terapia Intensiva Neonatal

\section{Introdução}

No contexto da internação neonatal, a participação dos homens, enquanto pais, é de extrema importância para o desenvolvimento do recémnascido $(R N)$, vínculo familiar e suporte à mãe. Para tanto, o pai também deve ter suas necessidades compreendidas e assistidas, visto que a hospitalização de um bebê tem marcante impacto na família. ${ }^{1}$ Este estudo teve como objetivo descrever os sentimentos paternos acerca da hospitalização do filho em Unidade de Internação Neonatal.

\section{Método}

Estudo exploratório e descritivo, com abordagem qualitativa, desenvolvido em uma unidade neonatal de um hospital público de ensino, no Estado de São Paulo. Os sujeitos foram pais de recém-nascidos hospitalizados. Excluiu-se pais: menores de dezoito anos, com distúrbios psiquiátricos diagnosticados, portadores de deficiência visual e/ou auditiva. A coleta de dados ocorreu por meio de entrevista semiestruturada, individualmente, em local privativo. As entrevistas foram gravadas, transcritas e analisadas segundo Análise Temática de Conteúdo proposta por Minayo. ${ }^{2}$

\section{Resultados e Discussão}

Realizou-se entrevista com 21 pais, com idades que variaram de 18 a 49 anos. Emergiram três categorias temáticas: 1) Sentimentos paternos; 2) Hospitalização como experiência árdua e 3) Enfrentamento da hospitalização por meio da fé. Os pais demandam suporte e apoio ao longo da experiência de hospitalização do filho tanto quanto as mães. Eles também vivenciam dificuldades e não sabem como lidar com elas, enquanto tentam dar suporte ao filho, mulher e família. Os profissionais de saúde devem dar oportunidades de expressão de inseguranças e sentimentos, bem como inclui-los como foco de cuidado. Assim, os pais perceberão a unidade neonatal como um local de confiança, onde podem demonstrar medos e vulnerabilidades, pois serão recebidos, ouvidos e incluídos, assim como as mães. ${ }^{3}$

\section{Conclusões}

Os pais vivenciam intensamente a hospitalização, mesmo quando não estão presentes na unidade. A equipe de enfermagem tem condição privilegiada para identificar necessidades paternas, visto que são os profissionais que estabelecem a aproximação entre pais e bebês, promovendo o estímulo ao vínculo. Assim, o cuidado intencional e direcionado aos pais poderá atenuar sentimentos negativos e favorecer os positivos que emergiram nos discursos dos pais do presente estudo.

\section{Agradecimentos}

Estudo financiado pelo Programa Institucional de Bolsas de Iniciação Científica (PIBIC) do Conselho Nacional de Desenvolvimento Científico e Tecnológico (CNPq) - CampinasSP.

1. Noergaard B, Johannessen H, Fenger-Gron J, Kofoed P, Ammentorp J Participatory action research in the field of neonatal intensive care. Developing an intervention to meet the fathers' needs - a case study. Journal of Public Health Research. 2016;5:744-751.

2. Minayo MCS. O desafio do conhecimento: pesquisa qualitativa em saúde. 14.ed.São Paulo: Hucitec; 2014.

3. Martel MJ, Milette I, Bell L, Tribble DSC, Payot A. Establishment of the Relationship Between Fathers and Premature Infants in Neonatal Units. Advances in Neonatal Care. 2016;16(5):390-398. 